\title{
Gender Differences in Psychosocial Risk and Protective Factors for Adolescent Alcohol Use and Misuse in Jamaica
}

\author{
P Whitehorne-Smith, K Morgan, W De La Haye, WD Abel
}

\begin{abstract}
Objective: The present study sought to determine if there were gender differences in the impact of five psychosocial risk and protective factors for adolescent alcohol use. The five factors considered by the study were family relationships, self-esteem, peer pressure, religious involvement and school performance.

Method: This was a cross-sectional quantitative study which utilized a 96-item self-administered questionnaire. The questionnaire captured key demographic and alcohol-related information. It also consisted of three standardized scales: the Cernkovich and Giordano's Family Relationship Scale, Rosenberg Self-esteem Scale and the CAGE questionnaire. Data were collected from students 12-18 years old in three schools in the Kingston and St Andrew area in Jamaica.

Results: There were 240 participants in the study, 121 males and 119 females. The findings revealed that there were no significant differences between male and female adolescent alcohol use in the last 30 days. There was also no significant difference between male and female adolescent risk of substance abuse. Logistic regression analysis of risk factor for each gender revealed that for males, their family relationship, peer pressure and self-esteem were significant predictors for alcohol use, while for females, peer pressure and school performance were significant predictors for alcohol use. Religious involvement was not found to be a significant protective factor for either gender.

Conclusion: Gender differences in risk and protective factors exist among Jamaican adolescents. Further research needs to be done to determine the extent of these differences which need to be considered in the development of prevention and intervention programmes.
\end{abstract}

Keywords: Adolescents, gender differences, protective factors, risk factors, substance use

WIMJ Open 2015; 2 (1): 19

\section{INTRODUCTION}

Alcohol has been widely recognized as the most misused substance worldwide, and the drug of onset and choice for most adolescents (1). While the problem of adolescent use and misuse affects all youth, there has been a noted shift in gender trends in recent research where female alcohol use is becoming similar to use in males (2-3).

Several psychosocial factors are seen repetitively throughout the literature as playing a central risk/protective role in adolescent alcohol use and misuse. For the purpose of this study, five factors were considered based on their frequency in the literature and the cultural context of Jamaica. These factors include family relationships, peer group influence, school performance, self-esteem and religiosity.

The present study sought to identify gender differences in the impact of psychosocial risk/protective factors of family relationships, self-esteem, peer pressure, religious involve-

From: Department of Community Health and Psychiatry, The University of the West Indies, Kingston 7, Jamaica.

Correspondence: Mrs P Whitehorne-Smith, Department of Community Health and Psychiatry, The University of the West Indies, Kingston 7, Jamaica. E-mail: patrice.whitehorne@yahoo.com ment and school performance on alcohol usage patterns among Jamaican adolescents. The general hypotheses of the study are that 1) there is a significant difference between psychosocial risk factors that influence female versus male adolescent alcohol misuse and 2) there is no significant difference between protective factors that influence female versus male alcohol misuse.

\section{SUBJECTS AND METHODS}

This was a cross-sectional study and access to the target population was gained via high schools. Simple random sampling was used to identify 20 schools selected from a list of all the high schools in the Kingston and St Andrew area for participation in this study. However, only three schools agreed to be a part of this study.

The sample size was ascertained by using alpha type I error of 0.05 , power of $90 \%$ and error factor of 10.5 from the dataset by Douglas (4). This calculation yielded a number of 223 as the minimum sample size needed for this study to be valid. This number was estimated based on the lifetime alcohol use across gender findings from Douglas (4). 


\section{Measures}

The study utilized a 96-item self-administered questionnaire. The questionnaire examined demographic information, religious practices, school performance and family relationship, as well as alcohol use and abuse patterns. Three standardized scales were used, the Cernkovich and Giordano's (1987) Family Relationship Scale (5), Rosenberg (1965) Self-esteem Scale (6) and the CAGE questionnaire.

Family Relationship Scale: this is a 28-item Likert-type scale with items answered on a five-point scale ranging from "strongly agree" to "strongly disagree" or "very often" to "never". It assesses parental involvement, control, supervision, affection, communication and trust of children. It has been widely used in studies related to juvenile delinquency and studies with a parent-child interaction component. The Family Relationship Scale (5) was found to have a reliability coefficient of 0.798 among the Jamaican pilot sample.

Rosenberg Self-esteem Scale: this is a 10-item Likert scale with items answered on a four-point scale ranging from "strongly agree" to "strongly disagree". It contains self statements in which respondents have to choose which point best represents their own feelings about self. This scale is widely used as it is able to ascertain persons' feelings about self as well as screen for discrepancies. The Rosenberg Selfesteem Scale (6) had a reliability coefficient of 0.85 among the Jamaican pilot sample.

CAGE questionnaire: Risk of alcohol abuse was measured utilizing the CAGE alcohol use standardized questionnaire which consists of four "yes" or "no" questions which measure an individual feeling the need to "cut down" on alcohol use, being "annoyed" by persons who criticize use, feelings of "guilt" associated with use and needing to use alcohol as an "eye opener" in the morning. Bernadt et al (7) determined that CAGE test scores $\geq 2$ had a sensitivity of $93 \%$ and a specificity of $76 \%$ for the identification of problem drinkers.

A pilot study was done in an effort to verify the reliability of the questionnaire. The pilot was based on a convenient sampling technique and targeted adolescents between the ages of 12 and 18 years. The pilot sample consisted of 50 participants - 25 females and 25 males; this number constituted $10 \%$ of the originally desired sample size for the study. Data analysis on the pilot data was done using Cronbach's alpha reliability coefficient.

Reliability analysis ran on the alcohol section of the questionnaire reflected a reliability coefficient of 0.98 for this section.

\section{Data analysis}

Descriptive and inferential statistics was performed on the data using the Statistical Package for the Social Sciences (SPSS) version 15. Chi-squared test of homogeneity and binary logistic regression were performed on appropriate data. All inferential statistical calculations were analysed based on a confidence interval of $95 \%$ error.

\section{RESULTS}

There were 240 participants - 121 males (50.4\%) and 119 females (49.6\%). Participants spanned across the grade levels of grade $7-10(\mathrm{M}=8.44, \mathrm{SD}=1.08)$ and were between the ages of 11 and $18(\mathrm{M}=13.97, \mathrm{SD}=1.29)$ years.

Of the 240 participants, $150(62.5 \%)$ reported having used alcohol in their lifetime, while 88 (36.7\%) respondents reported that they had never drank alcohol. A slight majority of respondents, $56.5 \%$ of males and $56.9 \%$ of females, reported that they had not consumed alcohol in the last 30 days. Of those who did report drinking alcohol in the last 30 days, most did so less than once per week; $34.6 \%$ were males and $31.9 \%$ were females (Table 1). There was no significant difference observed between gender and use of alcohol $(p>$ $0.05)$ in the last 30 days.

Table 1: Substance use in the last 30 days by gender

\begin{tabular}{lcc}
\hline Alcohol use & Males (\%) & Females (\%) \\
\hline None at all & 56.5 & 56.9 \\
Less than once per week & 34.6 & 31.9 \\
Three or four times per week & 2.6 & 6.9 \\
Five or more times per week & 6.3 & 4.2 \\
No response & 0 & 4.3 \\
\hline
\end{tabular}

The independent samples $t$-test analysis was done to identify if there was a difference between male and female risk for alcohol abuse. A mean of $0.75(\mathrm{SD} \pm 0.81)$ males and 0.66 ( $\mathrm{SD} \pm 0.86$ ) females were found to be currently abusing alcohol. However, there was no significant difference between males and females for substance abuse of alcohol $(\mathrm{t}$ $=0.65$, df (142), $p>0.05)$.

\section{Multivariate statistics}

Binary logistic regression analysis was done on aspects of the data to determine the extent to which the psychosocial risk factors of school performance, religious involvement, peer pressure, self-esteem and family relationship were predictive of substance use between genders. The predictors were analysed based on gender in order to specify factors of significance for each gender separately.

\section{Alcohol use \\ Males}

Logistic regression analysis revealed that family relationships $(\mathrm{B}=0.076, p<0.01, \mathrm{OR}=1.079,95 \% \mathrm{CI}: 1.01,1.14)$, self-esteem $(\mathrm{B}=-0.17, p<0.05, \mathrm{OR}=0.839,95 \% \mathrm{CI}: 0.724$, $0.791)$ and peer pressure $(\mathrm{B}=0.636, p<0.05, \mathrm{OR}=1.889$, 95\% CI: $1.01,3.54)$ were significant predictors of alcohol use in males. There was an inverse relationship between selfesteem and alcohol use, indicating that low self-esteem was also a significant predictor for alcohol use in males. Religious involvement and school performance were not found to be significant predictors of alcohol use in males. Findings also reveal that males who experienced peer pressure to use alcohol were two times more likely to actually 
use alcohol than those who did not report experiencing peer pressure (Table 2).

Table 2: Gender, alcohol use and five predictor variables

\begin{tabular}{lccc}
\hline Predictor & Beta $(\boldsymbol{\beta})$ & OR $(\mathbf{9 5 \%} \mathbf{C I})$ & Significance $(\boldsymbol{p})$ \\
\hline Males & & & \\
School performance & -0.171 & $0.843(0.293,2.45)$ & 0.843 \\
Religious involvement & -0.825 & $0.438(0.080,2.41)$ & 0.438 \\
Peer pressure & 0.636 & $1.889(1.01,3.54)$ & $0.047^{*}$ \\
Self-esteem & -0.176 & $0.839(0.724,0.791)$ & $0.019^{*}$ \\
Family relationship & 0.076 & $1.079(1.01,1.142)$ & $0.009^{* *}$ \\
& & & \\
Females & & & $0.025^{*}$ \\
School performance & -1.313 & $0.269(0.085,0.851)$ & 0.153 \\
Religious involvement & -1.456 & $0.233(0.032,1.72)$ & $0.002^{* *}$ \\
Peer pressure & 1.24 & $3.478(1.56,7.76)$ & 0.750 \\
Self-esteem & -0.023 & $0.978(0.851,1.12)$ & 0.237 \\
Family relationship & 0.027 & $1.027(0.983,1.073)$ & \\
\hline
\end{tabular}

${ }^{*} p<0.05,{ }^{* *} p<0.01, \mathrm{OR}=$ odds ratio, $\mathrm{CI}=$ confidence interval

\section{Females}

As it relates to females, peer pressure was found to be a significantly strong predictor of alcohol use $(\mathrm{B}=1.24, p<$ $0.01, \mathrm{OR}=3.478,95 \% \mathrm{CI}: 1.56,7.76)$ as well as school performance $(\mathrm{B}=-1.313, p<0.05, \mathrm{OR}=0.269,95 \% \mathrm{CI}: 0.085$, 0.851). However, school performance had an inverse relationship to alcohol use, indicating that poor school performance was a predictor for alcohol use. Peer pressure findings for females indicated that females who experienced peer pressure to use alcohol were three times more likely to actually use alcohol than those who did not report experiencing peer pressure. This finding suggests that peer pressure was a stronger predictor for female alcohol use than school performance (Table 2).

\section{DISCUSSION}

The findings of this study revealed that there was no significant difference between males and females in terms of alcohol use in the last 30 days. There was also no significant difference between genders and risk of alcohol abuse. These results support local and international research which has highlighted a closing gap between gender and substance use $(2,3,8)$.

There has also been a cultural shift toward equality between genders in every aspect of life extending to include the accessibility and acceptability of alcohol, tobacco and other drugs (ATOD) among women and by extension adolescent girls $(4,9)$.

The results further revealed that among males, family relationship was the strongest predictor of alcohol use, followed by self-esteem and peer pressure. While among females, peer pressure and school performance were the strongest predictors of alcohol use.

Of great significance is the finding that there is a positive relationship between peer pressure and alcohol use for both males and females. Peer pressure was the only risk factor identified as a predictor for alcohol use across genders, supporting the myriad of other studies that specify peer pressure as the most consistent contributor to adolescent alcohol use (10). However, what the present study adds to the catalogue is the finding that peer pressure was more significantly predictive for females than males. Female adolescents who experienced peer pressure to consume alcohol were three times more likely to use it, while males who experienced peer pressure were only two times more likely to use it.

Interestingly, there was a strong positive relationship between family relationship and alcohol use among males. This finding is inconsistent with previous research (11). However, the possibility exists that these families hold a positive attitude toward alcohol use. Within the Jamaica context, alcohol use is often seen as a rite of passage into adolescence and adulthood and its use is widely accepted in social gatherings. Hence, this finding is a crucial one which will require further exploration to determine the exact nature of this relationship.

There was an inverse relationship between self-esteem and alcohol use for males, suggesting that low self-esteem was a significant predictor of alcohol use. It is noteworthy that this was found to be significant among males only, as research conducted in other regions suggests no gender differences in this finding (12). Nonetheless, it is critical to note that ATOD use among males in many instances is an external expression of internal inadequacies that would not be picked up unless directly studied (13).

Moreover, for females, there was a significant inverse relationship between school performance and alcohol use, suggesting that poor school performance was a predictor for alcohol use among female adolescents. A significant body of research has shown that poor school performance is a predictor for substance use regardless of gender (13-15). However, in the present study, poor school performance was only predictive for female adolescent alcohol use.

Religious involvement was not found to be significantly predictive of alcohol use in either gender. This finding goes contrary to other studies which identified religious involvement as a protective factor against alcohol use (16, 17). This difference in findings could be linked to several factors such as differences in cultural context as well as how religiosity was measured in the present study.

\section{CONCLUSION}

The present study represents data collected from three institutions and consequently is not generalizable to schools throughout the island. Despite this, the study offers preliminary insight into the psychosocial risk/protective factors affecting youth and clearly highlights that these factors differ across gender. As such, it is important that future research seeks to explore further the psychosocial factors identified as significant in this study, as well as seek to identify others which may be significant in the Jamaican cultural context 
and how they impact on each gender specifically. This process will add to the development of gender-specific intervention that may be more impactful than generalized approaches to prevention and treatment.

\section{REFERENCES}

1. World Health Organization. Fact sheet on psychoactive substance use among adolescents in the WHO regions of the Americas. Geneva: WHO [cited $2013 \mathrm{Jul}$ 3]. Available from http://www.who.int/substance_abuse/ activities/prevention_factsheets/en/index.html

2. Schnike S, Di Noia J, Schwinn T, Cole K. Drug abuse risk and protective factors among black, urban adolescent girls: a group randomized trial of computer-delivered, mother-daughter intervention. Psychol Addict Behav 2006; 20: 496-500.

3. Substance Abuse and Mental Health Services Administration (SAMHSA). National Household Survey on Drug Abuse: main findings 1997. Washington, DC: SAMHSA; 1999 [cited 2013 Jul 20]. Available from: http://www.oas.samhsa.gov/nhsda/1997Main/nhsda1997mfWeb. htm

4. Douglas KG. Patterns of substance use and abuse among post primary students. Kingston: Planning Institute of Jamaica, Policy Development Unit; 2000.

5. Cernkovich SA, Giordano P. Family relationships and delinquency. Criminology 1987; 25: 295-319.

6. Rosenberg M. Society and the adolescent self-image. Princeton, NJ: Princeton University Press: 1965.

7. Bernadt MW, Mumford J, Taylor C, Smith B, Murray RM. Comparison of questionnaire and laboratory tests in the detection of excessive drinking and alcoholism. Lancet 1982; 6: 325-8.

8. National Council on Drug Abuse. National Secondary School Survey 2006. Washington, DC: The Organisation of American States/InterAmerican Drug Abuse Control Commission (OAS/CICAD); 2006.

9. Pilkington H. Beyond 'peer pressure': rethinking drug use and 'youth culture'. Int J Drug Policy 2007; 18: 213-24.

10. Deas D, Thomas S. Comorbid psychiatric factors contributing to adolescent alcohol and other drug use. Alcohol Res Health 2002; 26: $116-21$.
11. Scheer SD, Borden LM, Donnermeyer JF. The relationship between family factors and adolescent substance use in rural, suburban and urban settings. J Child Fam Stud 2000; 9: 105-15.

12. Newcomb MD, Maddahian EM, Bentler P. Risk factors for drug use among adolescents: concurrent and longitudinal analyses. Am J Public Health 1986; 76: 525-31.

13. Beman SD. Risk factors leading to adolescent substance abuse. Adolescence 1995; 30: 201-8.

14. Leatherdale ST, Hammond D, Ahmed R. Alcohol, marijuana and tobacco use patterns among youth in Canada. Cancer Causes Control 2008; 19: 361-9.

15. Hawkins JD, Catalano FR, Miller J. Risk and protective factors for alcohol and other drug problems in adolescence and early adulthood: implications for substance abuse prevention. Psychol Bull 1992; 112: 64-105.

16. Miller L, Davies M, Greenwald S. Religiosity and substance use and abuse among adolescents in the National Comorbidity Survey. J Am Acad Child Adolesc Psychiatry 2000; 39: 1190-7.

17. Albrecht SL, Amey C, Miller MK. Patterns of substance abuse among rural black adolescents. J Drug Issues 1996; 26: 751-81.

Submitted 13 Oct 2014

Accepted 27 Oct 2014

Published 16 Mar 2015

Online: http://www.mona.uwi.edu/wimjopen/article/1617

(C) Whitehorne-Smith et al 2015

This is an open access article made freely available under Creative Commons Attribution 4.0 International (CC BY 4.0). Users are free to share, copy and adapt this work as long as the copyright holder (author) is appropriately and correctly credited. See http:// creativecommons.org/licences/by/4.0/deed.en_us for more information. 